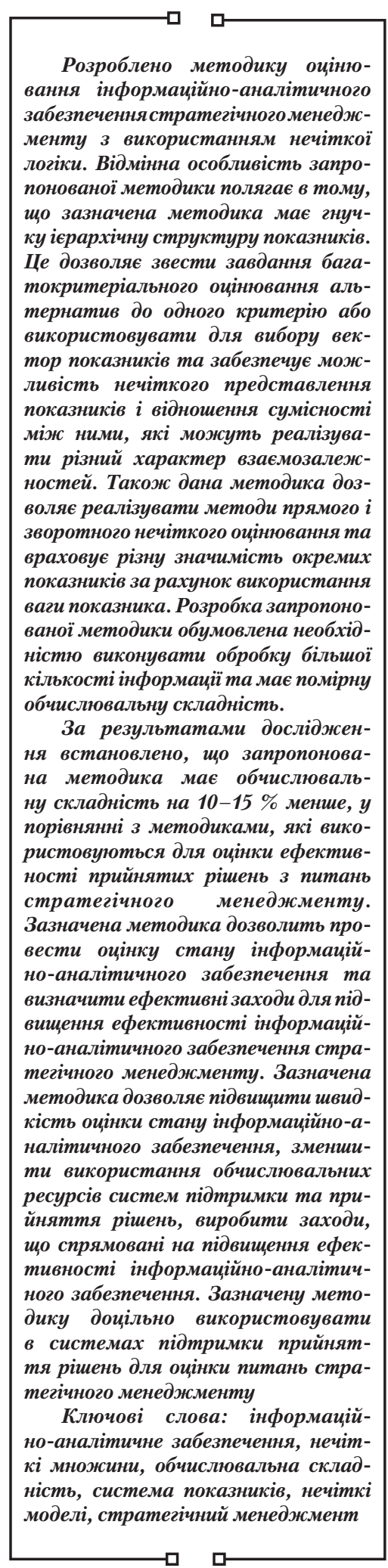

Received date 18.08.2019

Accepted date 13.11.2019

Published date 25.12.2019
UDC $355 / 359$

DOI: $10.15587 / 1729-4061.2019 .184394$

\section{DEVELOPMENT OF A METHOD OF FUZZY EVALUATION OF INFORMATION AND ANALYTICAL SUPPORT OF STRATEGIC MANAGEMENT}

\author{
I. Alie in ykov \\ Adjunct
}

Institute of State Military Management*

K. A. Th a m e r

$\mathrm{PhD}$, Head of Department

Department of Informatics

Kuliyyah Al-Maarif University College

Karrada str., 3, Ramadi, Republic of Iraq, 31001

Y u. Zhuravsk yi

Doctor of Technical Sciences Scientific Center

Zhytomyr Military Institute named after S. P. Koroliov Myru ave., 22, Zhytomyr, Ukraine, 10004 O. Sov a

Doctor of Technical Sciences, Head of Department Department of Automated Control Systems Military institute of telecommunications and informatization named after Heroes of Kruty Moskovska str., 45/1, Kyiv, Ukraine, 01011

N. S mirnova

Doctor of Technical Sciences, Associate Professor

Department of Road Building and Maintenance Kharkiv National Automobile and Highway University Yaroslava Mudroho str., 25, Kharkiv, Ukraine, 61002

R. Z h yvotovsky i

$\mathrm{PhD}$, Senior Researcher, Head of Research Department**

S. Hat se n ko

$\mathrm{PhD}$, Deputy Head of Department Department of Intelligence* S. Pe truk

Deputy Head of Scientifically-Research Department**

R. $\mathbf{P} \mathbf{i} \mathbf{k} \mathbf{u} \mathbf{~}$ Institute of Information Technology*

A. Shyshat skyi

$\mathrm{PhD}$, Head of Research Laboratory Research Laboratory of Electronic Warfare Development*** E-mail: ierikon12@gmail.com *Ivan Chernyakhovsky National Defense University of Ukraine Povitroflotskyi ave., 28, Kyiv, Ukraine, 03049

**Research Department of the Development of

Anti-Aircraft Missile Systems and Complexes *** $* * *$ Central Scientifically-Research Institute of Arming and Military Equipment of the Armed Forces of Ukraine

Povitroflotskyi ave., 28, Kyiv, Ukraine, 03049

Copyright (C) 2019, I. Alieinykov, K. A. Thamer, Yu. Zhuravskyi, O. Sova, N. Smirnova, R. Zhyvotovskyi, S. Hatsenko, S. Petruk, R. Pikul, A. Shyshatskyi This is an open access article under the CC BY license (http://creativecommons.org/licenses/by/4.0)
1. Introduction

In the process of strategic management, the central place is occupied by the development and adoption of manage- ment decisions, which in modern conditions are impossible without effective information and analytical support. In this case, strategic management is understood to be the purposeful activities of relevant officials to maintain the proper 
condition of management objects, planning and preparation of strategic measures [1].

The basis of strategic management is the decision of the manager (head), which is a certain procedure and ways of fulfilling strategic objectives. Strategic decision making is one of the most important functions of the manager in object management [1].

Therefore, the validity and timeliness of the manager's decision are the most important task of relevant officials and analytical units in strategic management.

The effectiveness of performing this complex task by officials greatly depends on decision-making methods, the improvement of which is based on integrated automation and informatization [1].

Thus, the creation and implementation of new high-performance automated systems and information technology of support and decision-making in the practice of modern managers are one of the most important areas of strategic management improvement.

Currently, software systems are being actively developed to support strategic decision-making that will improve the effectiveness of information and analytical support of officials.

Among the factors that stimulate the development of this class of software systems is the increasing role in solving poorly structured and difficult to formalize tasks under uncertainty and inaccuracy, which are characteristic features of description of causal relationships between elements of the situation.

Currently, three main approaches are the most common to solve the problems of accounting for the regularities of strategic processes. The first, analytical, uses their phenomenal description, obtained on the basis of deductive inference from more general laws (regularities). In the second, simulation, regularities of processes are taken into account in the construction of their mathematical models, and the models themselves can in some sense be considered as a partial tool for describing the regularities of management processes. Methodologically, both approaches are interconnected within a single hierarchical model system. In the third approach, the identification of laws (regularities) of the managed processes is based on a joint analysis of initial data and results of process modeling in different options of the situation, as well as adoption and implementation of management actions.

The first approach is used to build models of qualitative analysis of processes under the highest uncertainty of strategic planning, characteristic of the level of top management of state structures and corporations. The main feature of qualitative analysis models consists is that the results are generally not expressed in numerical scales (the dynamics of development - bifurcations - phase portrait of the socioeconomic macrosystem), which makes them unusable at the lower levels of planning.

The second approach is the most common. However, it does not provide a clear description of the regularities of management processes in the form of causal chains for individual elements of the situation. Such mathematical models are only a tool for predicting the possible course and the result of management processes under given conditions and decisions. Formation of causal chains that reveal the mechanisms of relevant laws (regularities) requires purposeful full-scale experimentation with models. As the studies show, these models are one of the main inconsistencies of existing information-analytical technologies of strategic decision-making with the goals and objectives of system analysis and, as a consequence, insufficient quality of strategic decision-making using mathematical modeling.

In recent decades, there has been an increasing tendency to use artificial intelligence methods. However, their application to existing strategic management systems is largely limited to an expert approach in the interests of automation and informatization of certain stages of information preparation while making a strategic decision.

The works [2-6] present studies on the development of methods (approaches) for multicriteria evaluation of complex objects. As the mathematical apparatus in these works, the fuzzy set theory, hierarchy analysis and expert evaluation methods are used.

These approaches have the following disadvantages:

- provide only general evaluation and distract from seeing specific relations between objects;

- complexity of processing heterogeneous data of quantitative and qualitative nature;

- limitations of model dimensions;

- complexity of decision-making under uncertainty.

In such circumstances, it is important to develop multi-criteria methods for evaluating complex objects and alternatives of strategic management.

Against this background, the use of fuzzy set theory and fuzzy logic for support and decision-making systems is a relevant direction for further research into support and decision-making systems in the interests of strategic management.

\section{Literature review and problem statement}

In [8], an agent-based approach used in a multiagent information-analytical system is described and problems of information support for decision-making are considered. The disadvantages of this approach include the limited representation of complex systems, namely, none of the agents has an idea of the whole system.

The paper [9] presents an operational approach to spatial analysis in the maritime industry for the quantitative assessment and mapping of associated ecosystem services. This approach covers the three-dimensionality of the marine environment, considering separately all marine areas (sea surface, water column and seabed). In fact, the method builds 3-dimensional models of the sea by estimating and mapping each of the three marine domains by adopting representative indicators. The disadvantages of this method include the impossibility of flexible adjustment (adaptation) of estimation models while adding (excluding) indicators and changing their parameters (compatibility and significance of indicators).

The paper [10] presents a machine learning model for the automatic identification of requests and provision of information support services that are exchanged between members of the Internet community. This model is designed to handle a large number of messages from users of social networks. The disadvantages of this model are the lack of mechanisms for evaluating the adequacy of decisions and high computational complexity.

The method of analysis of large data sets is presented in [11]. This method is aimed at finding hidden information in large data sets. The method involves operations of generating analytical baselines, reducing variables, identifying 
sparse features, and specifying rules. The disadvantages of this method include the inability to consider different strategies for evaluating decisions.

In [12], an approach to estimating the cost of living of a client in the air transportation industry is proposed. In this approach, the regression model is first used, followed by the indirect estimation model. Finally, the results of the evaluation are compared using both evaluation models. The disadvantages of this approach include the inability to determine the adequacy of evaluation.

In [13], an approach to quantitative evaluation intended to evaluate the optimal selection and/or testing of analytical methods is presented. Objective criteria related to analytics, sustainability, environmental impact and economic costs are estimated by determining the penalty points divided into five different blocks. For each block, the overall qualification is scaled from 0 to 4 and depicted on a regular hexagonal icon to compare analytical procedures. The disadvantages of this approach are the inability to increase the number of evaluated indicators.

In [14], the mechanism of transformation of information models of construction objects into their equivalent structural models is presented. This mechanism is intended to automate the necessary operations of conversion, modification and addition during such information exchange. The disadvantages of this approach include the inability to assess the adequacy and reliability of the information transformation process.

In [15], an analytical web platform is developed to investigate the geographical and temporal distribution of incidents. The web platform contains several dashboards with statistically significant results for territories. The web platform includes certain external sources of data on social and economic issues that allow examining the relationship between these factors and distribution of incidents at different geographical levels. The disadvantages of this analytical platform include the inability to assess the adequacy and reliability of the information transformation process, as well as high computational complexity.

In [16], a method of fuzzy hierarchical evaluation of library service quality is developed. This method allows evaluating the quality of libraries by the set of input parameters. The disadvantages of this method include the inability to assess the adequacy and reliability of evaluation.

The paper [17] compares the effectiveness of two methods of analytical hierarchy estimation and fuzzy analytical hierarchy method. The advantages and disadvantages of these methods are presented. The disadvantages include the lack of consideration of the compatibility of irregularly significant indicators and the inability to assess the adequacy of the decisions taken.

The paper [18] analyzes 30 algorithms for processing large data arrays. Their advantages and disadvantages are shown. It is found that the analysis of large data sets should be performed in layers, occur in real-time and be able to self-study. The disadvantages of these methods include high computational complexity and inability to test the adequacy of the estimates obtained.

In [19], an approach to evaluating input data for support and decision-making systems is presented. The essence of the proposed approach lies in the clustering of the basic set of input data, their analysis, followed by system training. The disadvantage of this approach is the gradual accumulation of assessment and training errors due to the inability to assess the adequacy of the decisions made.

The paper [20] presents an approach to processing data from different sources of information. This approach allows processing data from different sources. The disadvantages of this approach include low accuracy of assessment and inability to verify assessment accuracy.

In [21], a comparative analysis of existing decision support technologies is performed, namely: hierarchy analysis method, neural networks, fuzzy set theory, genetic algorithms, and neuro-fuzzy modeling. The advantages and disadvantages of these approaches are indicated. Areas of their application are defined. The method of hierarchy analysis has been shown to work well with full initial information, but due to the need to compare alternatives by experts and choose evaluation criteria, it is highly subjective. The use of fuzzy set theory and neural networks is justified for risk and uncertainty forecasting problems.

In [22] the problematic aspects of information-analytical support of strategic decision-making in modern management are considered. The role and place of the process of management decision-making in strategic planning are clarified. Existing approaches for accounting the regularities and result of strategic processes are analyzed. In the course of the analysis, it is found that approaches and methods of the modern model theory in management systems that allow carrying out a linguistic approximation of mathematical models of cybernetic systems are of particular interest. This approximation ensures the highest level of abstract description of systems, which allows identifying the most common concepts and exploring the relationships between them. However, the results obtained are not fully applicable to organizational management systems. It is proposed to use fuzzy sets theory and neural networks to solve strategic management problems.

The paper [23] describes tools and methods for analyzing and processing the information on the number and quality of personnel of the Ministry of Defense of the Czech Republic. The disadvantages of this approach include high computational complexity, inability to assess the adequacy and reliability of the decisions made.

In [24], approaches to processing constantly updated information circulating in social information communications are described, namely: active use of content monitoring techniques, content analysis in this process. The disadvantages of these methods include their great computational complexity.

In [25], a system of hierarchical fuzzy estimation of the factors influencing the process of rice cultivation is presented. The disadvantages of this technique include the accumulation of estimation errors due to the inability to evaluate the adequacy of the result obtained.

In [26], a methodology for determining and evaluating the strategic economic potential of theoretical and methodological foundations of forming and assessing the level of the strategic economic potential of economic systems is developed. This methodology is based on the hierarchy analysis method. The disadvantages of this methodology include the dependence of the results obtained on the competence of experts and high computational complexity.

In [27], an approach to determining the influence of factors affecting the efficiency of economic activity on the economy of integrated structures is developed. This approach is based on the peer review method. The disad- 
vantages of this approach include the dependence of the results obtained on the competence of experts and high computational complexity.

In [28], a systematic approach to evaluating the effectiveness of strategic plan implementation is developed. This system approach is based on the peer review method. The disadvantages of this system approach include the dependence of the results obtained on the competence of experts and high computational complexity.

The review of the papers [1-28] showed that the overwhelming majority are based on the use of general scientific methods, such as systematic, comparative, structural and functional analysis, expert assessment, scenario analysis of socioeconomic systems and theoretical and informational approach.

Common limitations of existing multi-criteria fuzzy alternative assessment methods are:

- complexity of forming a multi-level evaluation structure;

- lack of consideration of the compatibility of unevenly significant indicators;

- lack of ability to jointly perform forward and backward evaluation tasks with the support of choosing the best decisions.

In order to create decision support software, it is necessary to develop fuzzy evaluation methods that must satisfy the following set of requirements:

- ability to form a generalized evaluation indicator and make decisions based on sets of partial indicators that vary with a complex multi-level evaluation structure;

- ability to aggregate heterogeneous indicators (both quantitative and qualitative) of evaluation and choose decisions, which differ in measuring scales and ranges of values;

- taking into account the compatibility and different significance of partial indicators in the generalized evaluation of decisions;

- consideration of different decision-making strategies;

- flexible adjustment (adaptation) of evaluation models while adding (excluding) indicators and changing their parameters (compatibility and significance of indicators);

- ensuring the possibility of implementing forward evaluation of a generalized indicator on the basis of partial indicators, backward evaluation and joint implementation of forward and backward evaluation within a single model.

It is proposed to develop a methodology that would allow the evaluation of information and analytical support of strategic management, be flexible, implement forward and backward evaluation within a single model.

\section{The aim and objectives of the study}

The aim of the study is to develop a methodology of fuzzy evaluation of information and analytical support of strategic management. This will make it possible to take into account a larger number of factors affecting the timeliness of information and analytical support of strategic management, as well as having different units of measure and nature.

To achieve this aim, the following objectives were set:

- to develop a fuzzy evaluation model for creating software tools to support strategic management decision making;

- to develop an algorithm of fuzzy evaluation of information and analytical support of strategic management.

\section{Development of a fuzzy evaluation model for creating software tools to support strategic management decision-making}

To develop a methodology of fuzzy evaluation of the activities of officials, it is necessary to formalize the process of fuzzy evaluation of information and analytical support. The authors' research is proposed to carry out by developing a fuzzy evaluation model, as an integral part of the methodology of evaluating the information and analytical support of strategic management.

Let there be a set of indicators whose values reflect the results of measuring/evaluating the relevant properties of a set of complex objects or alternatives.

All sets of indicators are broken down by hierarchy levels. At each hierarchy level, the indicators form subsets, each corresponding to an indicator adjacent to it with a higher hierarchy level. At each hierarchy level, starting with the second, there may be indicators that do not form subsets at a lower level ("leaves"). At the first hierarchy level, there is a subset of one (generalized) indicator.

Each indicator is assigned a weight. Indicators belonging to one subset form a fuzzy compatibility relation.

The fuzzy evaluation model in the formalized form can be represented as follows:

$$
\left\{\begin{array}{l}
P^{(j)}=\left\{P_{1}^{(j)}, \ldots, P_{q}^{(j)}, \ldots, P_{Q}^{(j)}\right\}, j=1, \ldots, J ; q=1, \ldots, Q ; \\
P_{q}^{(j)}=\left\{p_{q, 1}^{(j)}, \ldots, p_{q, i}^{(j)}, \ldots, p_{q, n_{q}}^{(j)}\right\}, i=1, \ldots, n_{q} ; \\
p_{q, i}^{(j)} \leftrightarrow P_{s}^{(j+1)}=\left\{p_{s, 1}^{(j+1)}, \ldots, p_{s, m}^{(j+1)}, p_{s, n}^{(j+1)}\right\}, \\
j=1, \ldots, J-1 ; s=1, \ldots, S, m=1, \ldots, n_{s} ; \\
p_{q, i}^{(j)} \leftrightarrow w_{q, i}^{(j)}, j=1, \ldots, J ; \\
\tilde{R}_{q}^{(j)}=\left\{\left(\left(p_{q, k}^{(j)}, p_{q, l}^{(j)}\right) / c_{q, l}^{(j)}\right), j=1, \ldots, J ; k, l \in\left\{1, \ldots, n_{q}\right\}\right\},
\end{array}\right.
$$

where $J$ is the number of levels of the model hierarchy; $Q$ is the number of subsets of indicators on the $j$-th hierarchy level; $s$ is the number of subsets of indicators on the $(j+1)$ hierarchy level; $n_{q}$ is the number of indicators from the subset $P_{q}^{(j)}$ of the $j$-th hierarchy level; $n_{s}$ is the number of indicators from the subset $P_{s}^{(j+1)}$ of the $(j+1)$ hierarchy level, which is attributed to the $i$-th indicator $p_{q, i}^{(j)}$ from the subset $P_{q}^{(j)}$ of the $j$-th hierarchy level; $w_{q, i}^{(j)}$ is the weight of the indicator $p_{q, i}^{(j)} ; \tilde{R}_{q}^{(j)}$ is the fuzzy compatibility between the indicators of the subset $p_{q, k}^{(j)}$ and $p_{q, l}^{(j)}$ from the subset $P_{q}^{(j)}$.

Fig. 1 shows a fragment of the fuzzy evaluation model of the proposed type.

The mentioned fuzzy evaluation model allows taking into account all the requirements, which apply to the conditions of evaluation and choice of decisions and characterized by the following properties:

- has a flexible hierarchical structure of indicators that allows reducing the task of multicriteria evaluation of alternatives to a single criterion or using a vector of indicators for selection. This provides an opportunity of fuzzy presentation of indicators and compatibility relations that can realize the diverse nature of relationships;

- allows the implementation of forward and backward fuzzy evaluation methods;

- takes into account the different importance of individual indicators by using the weight of the indicator; 
- contains the necessary set of formalization tools for software implementation;

- minimizes the impact of the person (expert) on the strategic evaluation process.

This model eliminates the disadvantages inherent in the known evaluation systems, especially:

- provides an assessment of the situation (the object) and the relationship between them;

- allows processing heterogeneous data of quantitative and qualitative nature;

- has unlimited model dimensions;

- allows describing an object and its relationships, simplifying decision-making under uncertainty.

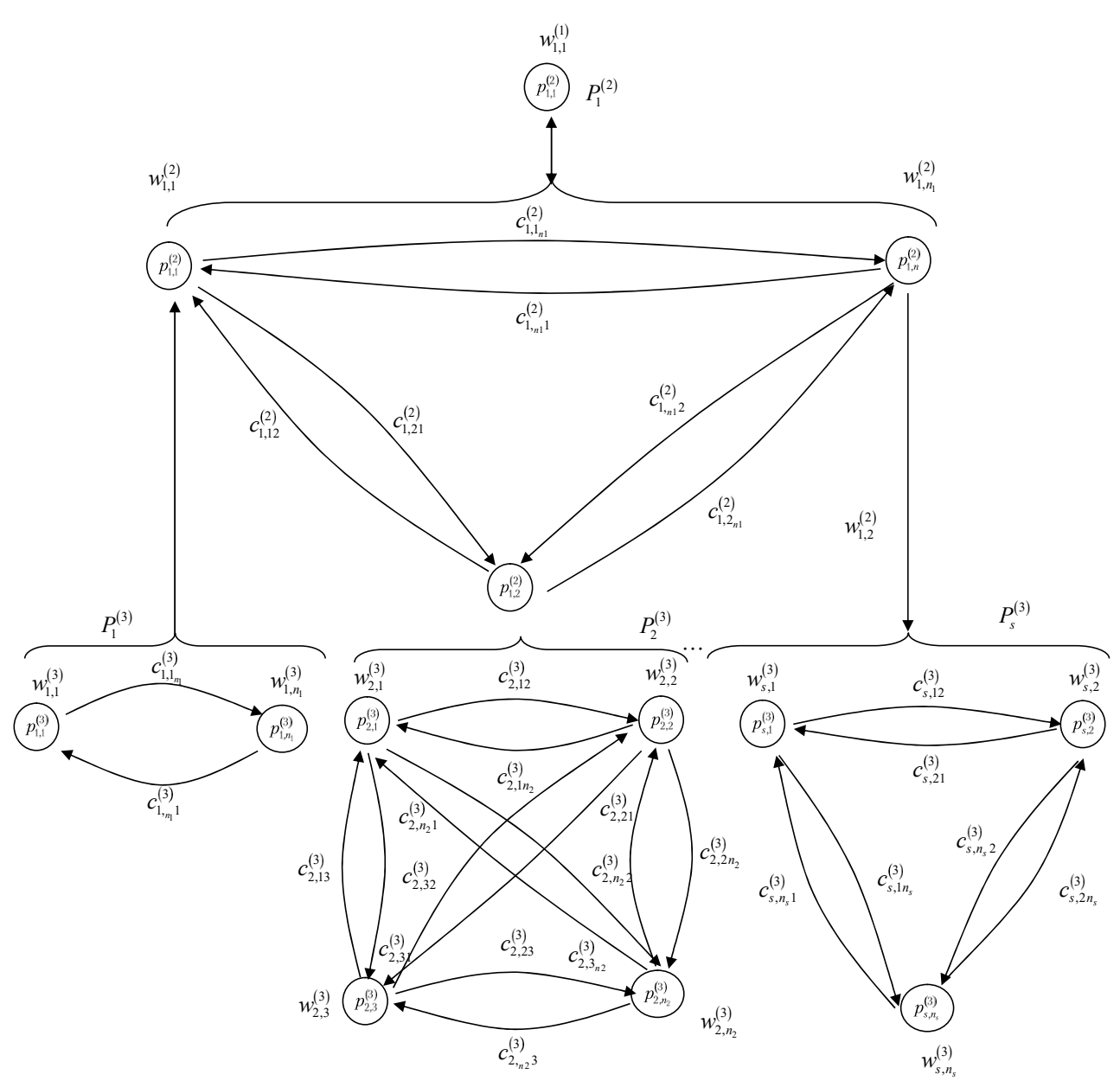

Fig. 1. Fragment of the fuzzy evaluation model support.
In its turn, this method directly evaluates the current state of the management object.

The initial stage is the input of initial data, namely evaluation indicators, which are developed in $[1,26]$.

Step 1. Construction of a fuzzy evaluation model.

Step 2. Determination of compatibility degree of aggregated indicators of information and analytical support.

Step 3. Justification of the set of convolution operations for aggregation of indicators of information and analytical

Step 4. Comparison of compatibility degrees of aggregated indicators with the operations of their convolution.

Step 5. Setting the evaluation strategy.

Step 6. Breakdown of the fuzzy compatibility relation into compatibility classes and selecting appropriate convolution operations.

Step 7. Modification of the fuzzy compatibility relation.

Step 8. Formation of the convolution structure of indicators of the fuzzy evaluation model.

Step 9. Setting the weights of indicators and fuzzy evaluation of alternatives.

Step 10. Development of recommendations to increase the efficiency of information and analytical support of officials and determining the rational order of their work.

Consider in detail the steps of the proposed evaluation methodology.

Step 1. Construction of a fuzzy evaluation model.

To build a fuzzy evaluation model, the following method is proposed, including:

- firstly, creating a hierarchical structure of evaluation indicators;

It is advisable to use this model as part of the methodology of fuzzy evaluation of information and analytical support of strategic management.

\section{Development of an algorithm of fuzzy evaluation information and analytical support of strategic management}

The method of fuzzy evaluation of information and analytical support of officials consists of the following main stages (Fig. 2).

I would like to point out that this method is used at the stage of evaluating the current state of the object (the relationship between them) and evaluating the effectiveness of management decisions and changes in the state of the management object.
- secondly, determining the weights of the indicators at each level of the model hierarchy; thirdly, determining fuzzy compatibility relations between indicators at each level of the model hierarchy.

To create a hierarchical structure of evaluation indicators, the following tasks must be solved:

- the indicators of each hierarchy level are grouped into subsets:

$$
P^{(j)}=\left\{P_{1}^{(j)}, \ldots, P_{q}^{(j)}, \ldots, P_{Q}^{(j)}\right\}, \quad j=1, \ldots, J ; \quad q=1, \ldots, Q,
$$

where $P_{q}^{(j)}$ is the $q$-th subset of indicators at the $j$-th hierarchy level of the model; $Q$ is the number of subsets of indicators at the $j$-th hierarchy level;

- each indicator $p_{q}^{(j)}$ on the $j$-th hierarchy level of the model is matched to the subset of indicators $P_{s}^{(j+1)}$ of the $(j+1)$-th level 


$$
\begin{aligned}
& p_{q, i}^{(j)} \leftrightarrow P_{s}^{(j+1)}=\left\{p_{s, 1}^{(j+1)}, \ldots, p_{s, m}^{(j+1)}, \ldots, p_{s, n}^{(j+1)}\right\}, \\
& j=1, \ldots, J-1 ; \quad s=1, \ldots, S ; \quad q=1, \ldots, Q ; \quad m=1, \ldots, n_{s},
\end{aligned}
$$

where $J$ is the number of hierarchy levels of the model; $Q$ is the number of subsets of indicators at the $j$-th hierarchy level; $S$ is the number of subsets of indicators at the $(j+1)$-th hierarchy level; $n_{q}$ is the number of indicators of the subset $P_{q}^{(j)}$ of the $j$-th hierarchy level; $n_{s}$ is the number of indicators of the subset $P_{s}^{(j+1)}$ of the $(j+1)$-th hierarchy level, which is correlated with the $i$-th indicator $p_{q, i}^{(j)}$ of the subset $P_{q}^{(j)}$ of the $j$-th hierarchy level of the model; $p_{q i}^{(j)}$ is the $i$-th indicator of the subset $P_{q}^{(j)}$ of the $j$-th hierarchy level of the model.

Known approaches and methods for analyzing complex systems, including peer review methods, can be used to create the hierarchical structure of indicators. It is worth noting that known approaches can also be used to determine the significance (weights) of all indicators at each hierarchy level of the model:

$$
p_{q, i}^{(j)} \leftrightarrow w_{q, i}^{(j)}, \quad j=1, \ldots, J ; \quad q=1, \ldots, Q ; \quad i=1, \ldots, n_{q},
$$

where $w_{q, i}^{(j)}$ is the weight of the indicator $p_{q, i}^{(j)}$.

Setting fuzzy compatibility relations between indicators has a particular interest since these fuzzy relations define the convolution operations of indicators in a fuzzy evaluation model. These fuzzy relations are set between the indicators from the subsets $P_{q}^{(j)}$ at each hierarchy level of the model:

$$
\begin{aligned}
& \tilde{R}_{q}^{(j)}=\left\{\left(\left(p_{q, k}^{(j)}, p_{q, l}^{(j)}\right) / c_{q, k l}^{(j)}\right)\right\}, \\
& j=1, \ldots, J ; \quad q=1, \ldots, Q ; \quad k, l \in\left\{1, \ldots, n_{q}\right\}
\end{aligned}
$$

where $\tilde{R}_{q}^{(j)}$ is the fuzzy compatibility relation between the indicators from the subset $P_{q}^{(j)}, c_{q, k l}^{(j)}$ is the compatibility degree of the indicators $p_{q, k}^{(j)}$ and $p_{q, l}^{(j)}$.

Depending on the specifics of the solved evaluation problem, compatibility can also be interpreted as correlation, mutual influence of partial indicators, and simultaneous achievement of values of compared partial indicators.

Also, at that stage, the adequacy of incoming information is evaluated and its usefulness is determined.

Step 2. Determination of compatibility degree of aggregated indicators.

Direct and indirect methods can be used to determine the compatibility degree of partial indicators. While using direct methods, the values of compatibility degrees $c_{q, k l}^{(j)} \in[0,1]$ of the indicators $p_{q, k}^{(j)}$ and $p_{q, l}^{(j)} \quad(k, l=1, \ldots, n$, where $n$ is the number of indicators) in the fuzzy compatibility relation $\tilde{R}_{q}^{(j)}=\left\{\left(\left(p_{q, k}^{(j)}, p_{q, l}^{(j)}\right) / c_{q, k l}^{(j)}\right)\right\}$ can be specified directly by the experts or obtained through experiments. Indirect methods are used when it is difficult to directly assess the compatibility degree of indicators.

In addition, the value $c_{q, k l}^{(j)}$ can be compared with criterion compatibility levels in increasing order of compatibility degree. For example, according to the Harrington scale, $C=\{N C$ is "Low level", $L C$ is "Below average level", $M C$ is "Medium level", $H C$ is "Above average level", $F C$ is "High level"\}:

$$
c_{k, l} \leftrightarrow c_{u} \in C=\{N C, L C, M C, H C, F C\}, \quad k, l=1, \ldots, n,
$$

where $u$ is the index of the element of the set $C$.

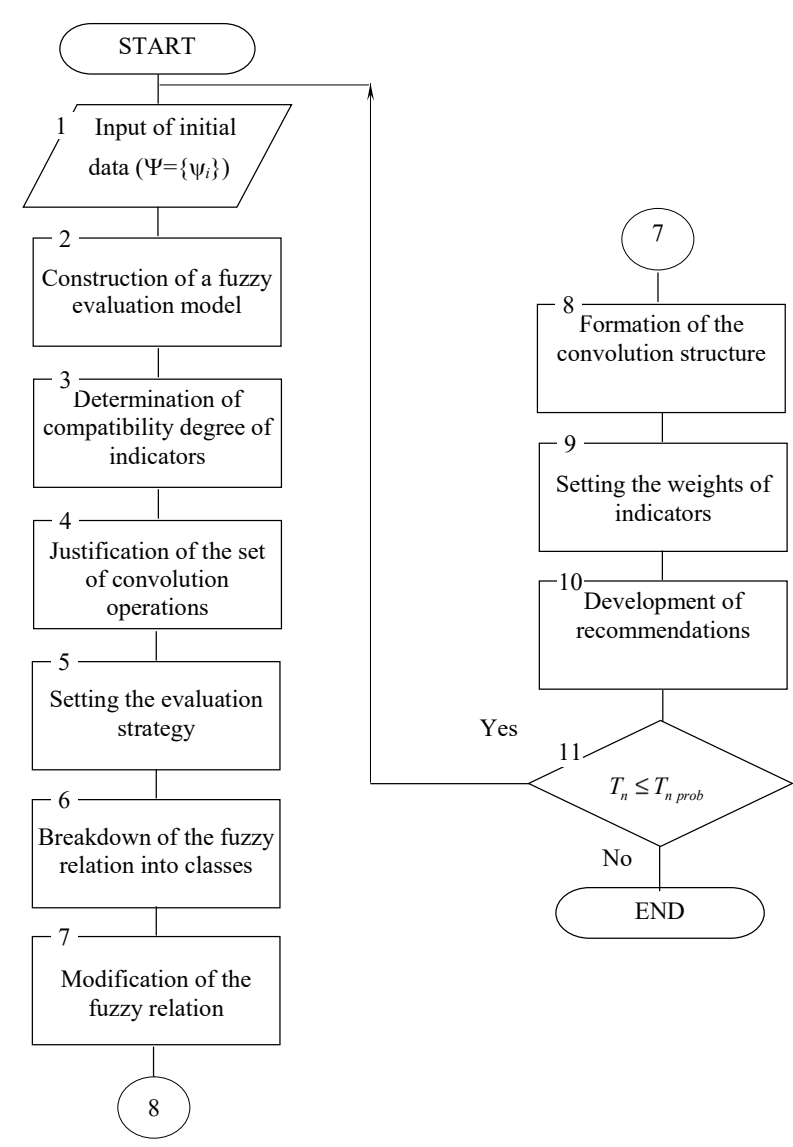

Fig. 2. Algorithm of the method of fuzzy evaluation of officials' activities

Fuzzy compatibility relations between the indicators from the subsets $P_{q}^{(j)}$, can be conveniently represented as fuzzy oriented graphs $\tilde{G}_{q}^{(j)}$ with fuzzy vertices and fuzzy arcs:

$$
\tilde{G}_{q}^{(j)}=\left(\tilde{P}_{q}^{(j)}, \tilde{R}_{q}^{(j)}\right)
$$

Since for all subsets of indicators, fuzzy compatibility relations are set in the same way, we move on to the next more illustrative designation and description of the fuzzy graph of indicators compatibility:

$$
\tilde{G}=(\tilde{P}, \tilde{R}),
$$

where $\tilde{P}=\left\{p_{i} / \mu_{p}\left(p_{i}\right)\right\}$ is the fuzzy set of indicators $p_{i} \in P$, $i \in\{1, \ldots, n\} ; \mu_{p}\left(p_{i}\right) \in[0,1]$ is the degree of belonging to the base set for the indicator $p_{i} ; \tilde{R}=\left\{\left(\left(p_{k}, p_{i}\right) / c_{k l}\right)\right\}, k, l=1, \ldots, n$, is the fuzzy set of oriented arcs each arc $\left(p_{k}, p_{l}\right)$ corresponds to the appropriate compatibility level $c_{k l} \in[0,1]$ of the indicators $p_{k}$ and $p_{l}$.

Fuzzy presentation of indicators allows using the developed apparatus of the fuzzy set and number theory for their estimation. Representing the same degree of compatibility between indicators based on fuzzy compatibility relations allows applying the approaches and methods of fuzzy relations theory to their analysis.

For the cases where it is difficult to directly assess the compatibility degree of indicators, a method based on pairwise comparison of all evaluation indicators and filling socalled tables of compatibility between the linguistic values of these indicators is proposed (Table 1). 
The number of rows and columns in the compatibility tables for each pair of indicators corresponds to the linguistic gradations of their scores. At the intersection of the row and the column, the symbol «+» is placed, if an appropriate combination of values for indicators compatible with the specified degree is possible. Otherwise the symbol «-» is put. The proportion of «+» symbols in Table 1 determines the degree of compatibility of one indicator with another.

In the case of a large number of indicators, to more accurately determine their compatibility degree, the number of gradations on linguistic scales should be increased.

To evaluate the compatibility of $n$ indicators, the expert fills $\frac{n !}{(n-2) !}$ compatibility tables.

Table 1

Example of compatibility table

\begin{tabular}{|c|c|c|c|c|c|c|}
\hline Medium & \multicolumn{6}{|c|}{ Efficiency } \\
\hline \multirow{6}{*}{ Reliability } & & Very bad & $\mathrm{Bad}$ & Medium & Good & Excellent \\
\hline & Very bad & + & + & + & + & + \\
\hline & $\mathrm{Bad}$ & + & + & + & + & - \\
\hline & Medium & + & + & + & - & - \\
\hline & Good & + & + & - & - & - \\
\hline & Excellent & + & - & - & - & - \\
\hline $\begin{array}{c}\text { Above } \\
\text { average } \\
\text { level }\end{array}$ & \multicolumn{6}{|c|}{ Reliability } \\
\hline \multirow{6}{*}{ Efficiency } & & Very bad & $\mathrm{Bad}$ & Medium & Good & Excellent \\
\hline & Very bad & + & + & + & + & + \\
\hline & $\mathrm{Bad}$ & + & + & + & + & + \\
\hline & Medium & + & + & + & + & + \\
\hline & Good & + & + & + & + & - \\
\hline & Excellent & + & + & + & - & - \\
\hline
\end{tabular}

Step 3. Justification of the set of operations for indicators aggregation.

In [1-12], the requirements for the developed fuzzy evaluation models, as well as for the methods of forward and backward fuzzy evaluation on their basis for support and decision making are formulated. These requirements are largely determined by the choice of convolution operations and the way they are compared with the compatibility degree of aggregated indicators.

Also, based on the established requirements to minimizing resources and time to prepare for evaluation, it is expected to use fuzzy analytical convolutions instead of FIS (Fuzzy Interface System) models. This is due to the complexity of setting up and using FIS models in the forward and backward fuzzy evaluation of alternatives.

While evaluating and choosing alternatives, the decision-maker can be guided by different strategies, the extreme options of which are reaching the lowest value of all indicators or achieving the maximum value of at least one of the indicators. In the double case, these extreme strategies correspond to convolution operations of the indicators $p_{k}$, $p_{l}: \min \left(p_{k}, p_{l}\right)$ and $\max \left(p_{k}, p_{l}\right)$. To determine the degree of compromise of double convolution operations, it is suggested to use the parameter $\theta \in[0,1]$. However, the smaller the parameter $\theta$, the lower the degree of compromise of the indicators $p_{l}$ and $p_{k}$. The value of the parameter $\theta$ will be calculated according to the expression:

$$
\theta=\frac{v-v_{\min }}{v_{\max }-v_{\min }}
$$

where $v$ is the value of the "volume" below the surface of the function formed by applying the corresponding convolution operation; $v_{\min }$ and $v_{\max }-$ as a result of the operations $\min \left(p_{k}, p_{l}\right)$ and $\max \left(p_{k}, p_{l}\right)$, respectively.

The analysis of the most common double convolution operations having the above properties $[2-7,17]$ is performed and the values of the parameter $\theta$ are determined for these operations. Table 2 shows the convolution operations that satisfy these requirements in increasing order of the parameter $\theta$.

From Table 2, we can conclude that for extreme evaluation strategies, the value of the parameter $\theta=0$ corresponds to the convolution operation $\min \left(p_{k}, p_{l}\right), \quad \theta=1-$ to the convolution operation $\max \left(p_{k}, p_{l}\right)$. Other convolution operations correspond to the parameter values $0<\theta<1$.

While constructing evaluation models, there may be situations where compatibility degrees (or criterion compatibility levels) of several (more than two) indicators coincide.

To get a generalized estimate, it is necessary to consistently convolute these indicators using the same operation. In this case, the result of evaluation is affected by the presence of the associative property of the used operation. Accordingly, the requirement of the associative property for convolution operations must be considered.

Further analysis of the use of associative convolution operations leads to the conclusion that the use of the operation

$$
\frac{p_{k} p_{l}}{1-p_{k}-p_{l}+2 p_{k} p_{l}}
$$

is inappropriate for the proposed model due to a significant increase in uncertainty in backward fuzzy estimation.

Table 2

Appropriate convolution operations

\begin{tabular}{|c|c|c|}
\hline No. & $\begin{array}{c}\text { Convolution operation of indicators } \\
p_{k} \text { and } p_{l}\end{array}$ & Parameter value $\theta$ \\
\hline 1 & $\min \left(p_{k}, p_{l}\right)$ & 0.0 \\
\hline 2 & $\operatorname{med}\left(p_{k}, p_{l} ; 0.25\right)$ & 0.16 \\
\hline 3 & $\frac{2 p_{k} p_{l}}{p_{k}+p_{l}}$ & 0.23 \\
\hline 4 & $\frac{\sqrt{p_{k} p_{l}}}{2}$ & 0.33 \\
\hline 5 & $\frac{\min \left(p_{k}, p_{l} ; 0.5\right)}{1-\left|p_{k}-p_{l}\right|}$ & 0.5 \\
\hline 6 & $\frac{p_{k}+p_{l}}{2}$ & 0.5 \\
\hline 7 & $\frac{p_{k}+p_{l}-p_{k} p_{l}}{1+p_{k}+p_{l}-2 p_{k} p_{l}}$ & 0.5 \\
\hline 8 & $\frac{\max (x, y)}{1+|x-y|}$ & 0.5 \\
\hline 9 & $\frac{p_{k} p_{l}}{1-p_{k}-p_{l}+2 p_{k} p_{l}}$ & 0.5 \\
\hline 10 & $1-\sqrt{\left(1-p_{k}\right)\left(1-p_{l}\right)}$ & 0.5 \\
\hline 11 & $\operatorname{med}\left(p_{k}, p_{l} ; 0.75\right)$ & 0.67 \\
\hline 12 & $\max \left(p_{k}, p_{l}\right)$ & 0.84 \\
\hline 13 & & 1.0 \\
\hline
\end{tabular}


The rest of the convolution operations satisfy all the requirements and make up a set of operations for comparison with compatibility degrees of indicators (Table 3).

Table 3

Reasonable set of convolution operations

\begin{tabular}{|c|c|c|}
\hline No. & $\begin{array}{c}\text { Convolution operation of indicators } \\
p_{k} \text { and } p_{l}\end{array}$ & Parameter value $\boldsymbol{\theta}$ \\
\hline 1 & $\min \left(p_{k}, p_{l}\right)$ & 0.0 \\
\hline 2 & $\operatorname{med}\left(p_{k}, p_{l} ; 0.25\right)$ & 0.16 \\
\hline 3 & $\operatorname{med}\left(p_{k}, p_{l} ; 0.5\right)$ & 0.5 \\
\hline 4 & $\operatorname{med}\left(p_{k}, p_{l} ; 0.75\right)$ & 0.84 \\
\hline 5 & $\max \left(p_{k}, p_{l}\right)$ & 1.0 \\
\hline
\end{tabular}

Step 4. Comparison of compatibility degrees of aggregated indicators with their convolution operations.

It can be noted that the three operations selected from the previous stage of convolution operations are essentially options of the same parameterized operation med with different parameter values. This feature is used for the proposed method of comparing the compatibility degree of indicators with the operations of their convolution.

In order to compare the compatibility degree of aggregated indicators with convolution operations, direct methods of establishing such compliance by an expert are generally used.

However, from the previous reasonable set of operations, it can be concluded that the whole set of compromise strategies provides a parameterized family of convolution operations:

$$
\operatorname{med}\left(p_{k}, p_{l} ; \alpha\right), \quad k, l \in\{1, \ldots, n\}, \quad a \in[0,1] .
$$

Moreover, the values of the parameter $\theta$ can use the compatibility degree of the aggregated indicators $p_{k}$ and $p_{l}$. To illustrate this, Fig. 3 presents the dependency of $\theta$ on $\alpha$.

Also, the values of the parameter $\alpha$ of the convolution operation $\operatorname{med}\left(p_{l}, p_{k}, \alpha\right)$ can be compared with the compatibility criterion levels of indicators. Table 4 shows an example of this comparison.

Step 5. Determination of evaluation strategy.

Evaluation strategy is determined on the basis of decision-maker's preferences, as well as features of evaluation objects and consists in specifying:

- firstly, the order of review of compatibility degrees of indicators, which determines the order of aggregation of indicators in the model;

- secondly, the procedures for recalculating compatibility degrees of indicators in their consistent convolution.

There are two main strategies of fuzzy evaluation:

- from the least compatible indicators to the most compatible indicators;

- from the most compatible indicators to the least compatible indicators.

Moreover, evaluation strategy can be set for the whole model as well as for each subset of indicators.

Step 6. Breakdown of the fuzzy compatibility relation into compatibility classes and selection of their convolution operations.

Consider the strategy of evaluation from the least compatible indicators to the most compatible indicators.

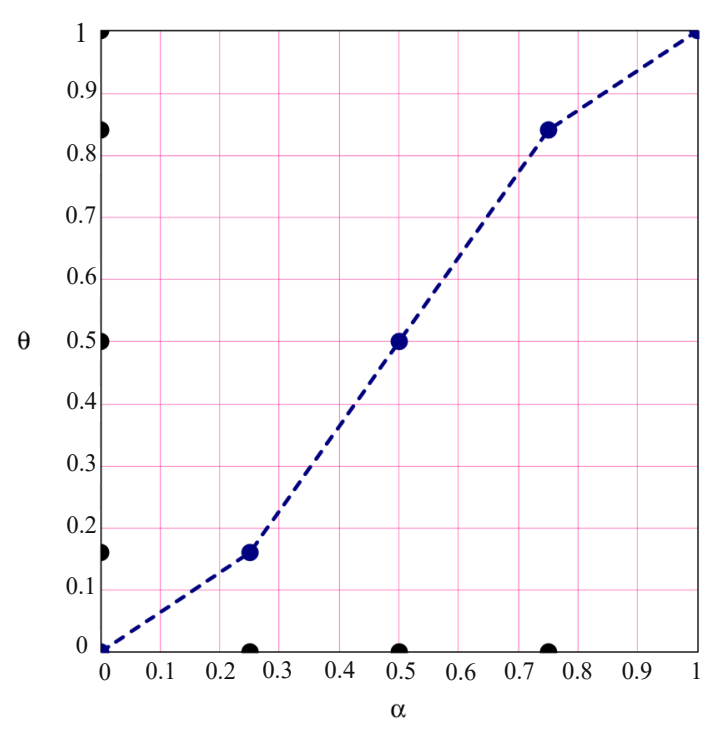

Fig. 3. Dependence of $\theta$ on $\alpha$ for the convolution operation $\operatorname{med}\left(p_{l}, p_{k}, \alpha\right)$

Table 4

Comparison of parameter values of convolution operation $\operatorname{med}\left(p_{l}, p_{k}, \alpha\right)$ with compatibility criterion levels of indicators

\begin{tabular}{|c|c|c|c|}
\hline \multirow{2}{*}{ No. } & \multirow{2}{*}{$\begin{array}{c}\text { Convolution operation } \\
\text { of indicators } p_{k} \text { and } p_{l}\end{array}$} & \multicolumn{2}{|c|}{$\begin{array}{c}\text { Compatibility criterion levels of } \\
\text { indicators } p_{l} \text { and } p_{k}\end{array}$} \\
\cline { 3 - 4 } & & Designation & Description \\
\hline 1 & $\operatorname{med}\left(p_{k}, p_{l} ; 0.0\right)$ & $N C$ & Low level \\
\hline 2 & $\operatorname{med}\left(p_{k}, p_{l} ; 0.25\right)$ & $L C$ & Below average level \\
\hline 3 & $\operatorname{med}\left(p_{k}, p_{l} ; 0.5\right)$ & $M C$ & Average level \\
\hline 4 & $\operatorname{med}\left(p_{k}, p_{l} ; 0.75\right)$ & $H C$ & Above average level \\
\hline 5 & $\operatorname{med}\left(p_{k}, p_{l} ; 1.0\right)$ & $F C$ & High level \\
\hline
\end{tabular}

The fuzzy compatibility relation of indicators can be broken down into so-called compatibility classes with respect to criterion compatibility levels.

Fig. 4, 5 show that the fuzzy compatibility relation $\tilde{R}$ relative to the NC criterion level ("Lack of compatibility") can be divided into two compatibility classes.

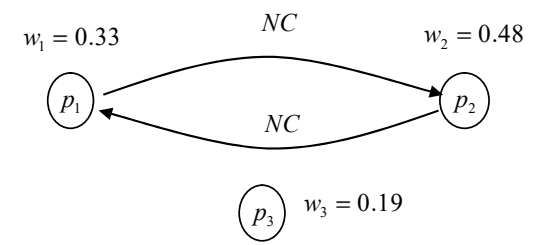

Fig. 4. Compatibility classes of fuzzy compatibility relation

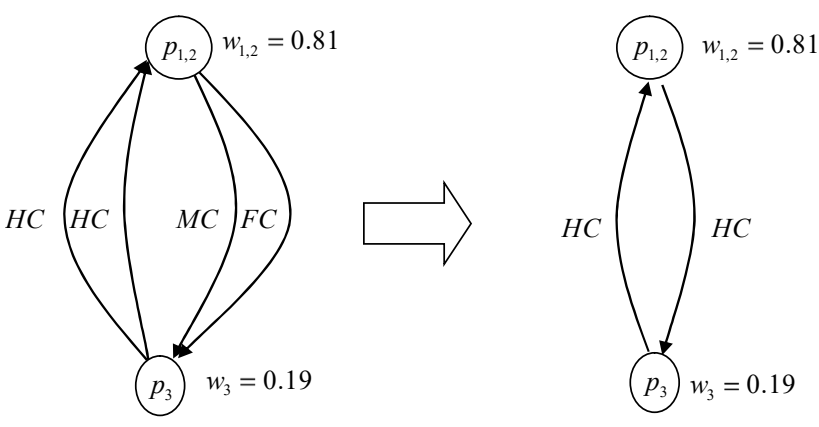

Fig. 5. Example of fuzzy compatibility relation modification 
To aggregate indicators within one compatibility class, the same operation corresponding to the set criterion level is used. And the order of convolution of indicators within one class is not important. In this case, the aggregated indicators $p_{1}$ and $p_{2}$, using the operation $\operatorname{med}\left(p_{1}, p_{2} ; 0,0\right)$ or $\min \left(p_{1}, p_{2}\right)$.

Step 7. Modification of fuzzy compatibility relation.

After convolution of indicators, it is necessary to carry out modification of the fuzzy compatibility relation and change compatibility degrees (levels) of the indicators taking into account the new aggregated indicator $p_{1,2}$ whose weight will be equal to the sum of the weights of aggregated indicators (Fig. 5).

Step 8. Formation of the convolution structure of indicators.

Steps 6 and 7 are repeated at all hierarchy levels of the fuzzy evaluation model, starting at the bottom and at each hierarchy level for all subsets of indicators.

The result is the convolution structure of indicators in the following form:

$$
h^{*}\left(p_{1}, \ldots, p_{n}\right)=h_{u}\left(h_{y}\left(\ldots\left(h_{t}\left(p_{1}, p_{2}\right), \ldots\right), p_{n-1}\right) p_{n}\right) .
$$

where $t, y, u$ are convolution operation indexes corresponding to different compatibility levels of indicators.

Step 9. Setting the weights of indicators and fuzzy evaluation of alternatives.

At this stage, for each of the evaluated alternatives $A=\left\{a_{1}, \ldots, a_{j}, \ldots, a_{m}\right\}$, the values of all indicators $\left\{p_{1}, \ldots, p_{i}, \ldots, p_{n}\right\}$ of the lower hierarchy level of the model are set.

The fuzzy value of the indicator $p_{i}$ of the alternative $a_{i}$ can generally be represented as a fuzzy set (number) $p_{i}=\left\{\left(p_{i} / \mu_{\tilde{p}_{i}}\left(p_{i}\right)\right)\right\}$, given on $p_{i} \in[0,1]$ by the values of the membership function $\mu_{\tilde{p}}\left(p_{i}\right) \in[0,1]$. In the particular case, the value of the indicator $p_{i}$ of the alternative $a_{i}$ can be represented by a clear value $p_{i}\left(a_{j}\right) \in[0,1]$. Further, unless otherwise stated, we will use clear values of indicators. Immediately prior to direct fuzzy evaluation, the significance of the indicators should be taken into account. The procedure of accounting for the significance of indicators is performed before the convolution for each pair of indicators $p_{k}$ and $p_{\partial}$ in accordance with the following expressions:

$$
\begin{aligned}
& p_{k}^{\prime}=p_{k}+\left(p_{k}-p_{l}\right) \cdot\left(w_{k}-\max \left(w_{k}, w_{l}\right)\right), \\
& p_{l}^{\prime}=p_{l}+\left(p_{l}-p_{k}\right) \cdot\left(w_{l}-\max \left(w_{k}, w_{l}\right)\right) .
\end{aligned}
$$

In the case of equal distribution of weights, the estimates of indicators do not change, if the weight of one indicator is less than the weight of the other, then the value of the indicator with less weight is adjusted, taking into account the difference between the values and weights of indicators.

Step 10. Development of recommendations to increase the efficiency of information and analytical support of officials and determining the rational order of their work.

While solving any task, including the implementation of measures of strategic management organization, the main criterion for the effectiveness of work is the ability to fulfill the tasks within a given time.

While planning strategic management activities, the manager and officials are guided by certain rules, apply different techniques and methods, which are interrelated and characterized by a relatively clear statement of tasks or work and regulation of the execution time. Decision-making on the use of forces and resources during the organization (planning) of strategic management can be made on the basis of subjective (intuitive, informal) approach [1].

One way to solve this problem is to increase the efficiency of officials in the adopted management cycle [1].

The indicators of efficiency include [1,26]:

- the mathematical expectation of management time $M_{T}$;

- probability of completing the management cycle at a given time $P_{y}$.

In this case, the duration of the critical path in the adopted cycle $T_{k}$, is taken as the mathematical expectation of management time and the probability of completing the management cycle at a given time is determined by the formula [1]

$$
P_{y}=\frac{1}{2}\left[1+\Phi\left(\frac{T_{d i r}-T_{k}}{\sigma_{y}}\right)\right],
$$

where $T_{d i r}$ is the directive time of completing the management cycle; $\Phi$ is the Laplace function; $\sigma_{y}$ is the standard deviation of time of work performance by the organization officials.

The objective function of choosing a rational work order for officials is as follows [27].

$$
U=\min \left\{M_{T}\right\} \text {, when } S=\text { const, } M_{T}<T_{\text {red }},
$$

where $S$ is the composition of forces and resources; $T_{\text {red }}$ is the time from receiving a task to being ready to complete it.

The increase of the efficiency of officials is possible due to the determination of rational volume and sequence of work by planning stages, redistribution of activities among stages with a focus on priority data preparation. Therefore, it is advisable to divide the work among the performers and assign reasonable deadlines for implementation [1, 26, 27].

According to the composition of officials and simulation data, the work is distributed among the officials. The distribution of responsibilities is carried out in such a way as to ensure compliance with the requirements of minimizing the management time (expression (2)), loading uniformity of performers and timeliness of completion of the management cycle.

The coefficients, assessing the loading of officials $\left(K_{n}\right)$, are calculated by the formula

$$
K_{n}=\frac{t_{n}}{T_{\max }^{n}},
$$

where $t_{n}$ is the total time spent by each official; $T_{\max }^{n}$ is the maximum duration of performing the whole complex of work by officials.

With the difference in the loading coefficients of officials no more than $5 \%$, it is possible to consider that the option of work distribution among them is rational. Otherwise, it is advisable to redistribute the work among officials.

The probability of completing the management cycle within the specified time is determined in accordance with the expression (3). The distribution of officials' responsibilities in each management cycle should be such that with the probability $P_{y}=0.9$, the mathematical expectation of the completion time of the accepted management cycles did not exceed the specified value. When the above conditions are fulfilled, the order of work can be considered rational and taken as a basis in practice. 


\section{Discussion of the results of developing methods of fuzzy evaluation of information and analytical support of strategic management}

The method of fuzzy evaluation of information and analytical support of strategic management is proposed. The simulation of the proposed method in the MathCad 14 software environment is carried out.

The fuzzy evaluation model to create software tools to support strategic management decision-making is developed. The advantage of this model is that it has the form of a hierarchy tree, which makes it universal to describe all types of analysis (decomposition) objects, which allows describing not only the object itself, but also its relations with other objects, using quantitative evaluation indicators.

During the research, the authors developed the algorithm of fuzzy evaluation of information and analytical support of strategic management, the graphical representation of which is shown in Fig. 2. We would also like to draw your attention to the fact that this algorithm justifies convolution operations (Step 3) and defines evaluation strategy (Step 5). This feature allows using it to solve a wide range of tasks.

To evaluate the effectiveness of the developed methodology for evaluating the information and analytical support of strategic management, its comparative assessment with the most popular software for enterprise management (strategic management) is performed:

- ARIS Business Performance Edition (IDS Scheer AG, Germany);

- IBM WebSphere Business Modeler (IBM, USA);

- System21 Aurora (Campbell Lee Computer Services Limited, Great Britain);

- SAP Strategic Enterprise Management (SAP, Germany);

- Hyperion Performance Scorecard (Oracle, USA),

- CA ERWin Process Modeler (CA, USA).

For comparative assessment, assessment of the real state of the company is performed. Everest Limited LLC (Kyiv, Ukraine) is used as a research object.

The results of the assessment of the real state of the company are given in Table 5, which presents the normalized evaluation results.

As can be seen from Table 5, the advantage of this method over the known ones is the reduction of computational complexity, which in turn increases the speed of strategic decision making regarding the management object.

The main advantages of the proposed evaluation methodology are:

- flexible hierarchical structure of indicators, which allows reducing the task of multicriteria evaluation of alternatives to one criterion or using a vector of indicators for selection;

- uniqueness of the assessment of the state of information and analytical support;

- wide scope (support and decision-making systems);

- simplicity of mathematical calculations;

- possibility of adjustment of the system of indicators during the work;

- possibility to synthesize the optimal structure of the support and decision-making system.

The disadvantages of the proposed methodology include:

- loss of information in assessing the state of information and analytical support through the construction of the membership function. This loss of information can be reduced by choosing the type of membership function for the practical implementation of the proposed methodology in support and decision-making systems. The choice of membership function depends on the computing resources of a particular electronic computing device;

- lower accuracy of estimation of a separate parameter of the state of information and analytical support;

- less accuracy compared to other estimation methods.

This method will allow:

- assessing the state of information and analytical support;

- identifying effective measures to improve the effectiveness of information and analytical support of strategic management;

- increasing the speed of assessment of the state of information and analytical support;

- reducing the use of computing resources of support and decision-making systems.

- developing measures aimed at improving the efficiency of information and analytical support

Table 5

Comparison of the computational complexity of the software and the developed methodology to evaluate the real state of the company

\begin{tabular}{|c|c|c|c|}
\hline No. & Name of software & $\begin{array}{c}\text { Number of } \\
\text { calcula- } \\
\text { tions }\end{array}$ & $\begin{array}{c}\text { Developed method } \\
\text { (by the number of } \\
\text { calculations) }\end{array}$ \\
\hline 1 & $\begin{array}{c}\text { ARIS Business Performance } \\
\text { Edition (IDS Scheer AG) }\end{array}$ & 67,000 & 58,960 \\
\hline 2 & $\begin{array}{c}\text { IBM WebSphere Business } \\
\text { Modeler (IBM) }\end{array}$ & 64,500 & 58,760 \\
\hline 3 & $\begin{array}{c}\text { System21 Aurora (Campbell } \\
\text { Lee Computer } \\
\text { Services Limited) }\end{array}$ & 57,000 & 48,450 \\
\hline 4 & $\begin{array}{c}\text { SAP Strategic Enterprise } \\
\text { Management (SAP) }\end{array}$ & 39,830 & 35,847 \\
\hline 5 & $\begin{array}{c}\text { Hyperion Performance } \\
\text { Scorecard (Oracle) }\end{array}$ & 46,200 & 40,194 \\
\hline 6 & $\begin{array}{c}\text { CA ERWin Process } \\
\text { Modeler (CA) }\end{array}$ & 43,050 & 37,023 \\
\hline
\end{tabular}

The results of analyzing the effectiveness of the proposed methodology show that its computational complexity is $10-15 \%$ less compared to the methods used to evaluate the effectiveness of the decisions presented in Table 5.

This study is a development of the authors' research, aimed at the development of methodological foundations for improving the effectiveness of information and analytical support published earlier [28-31].

The areas of further research should be aimed at reducing the computational cost of processing different types of data in special-purpose systems.

\section{Conclusions}

1. The fuzzy evaluation model for creating software tools to support strategic management decision-making is proposed. The essence of this fuzzy evaluation model for creating software tools to support strategic management decision-making consists in the fact that the object of evaluation is represented as a hierarchy tree.

This model eliminates the disadvantages inherent in the known evaluation systems, namely: 
- provides an assessment of the situation (object) and relations between them;

- allows processing heterogeneous data of qualitative nature;

- has unlimited model dimensions;

- allows describing the object and its relations, which simplifies decision-making under uncertainty.

Given this, the model should be used as part of the methodology of fuzzy evaluation of information and analytical support of strategic management.

2. In this research, the authors developed an algorithm of fuzzy evaluation of information and analytical support of strategic management. The novelty of this algorithm is the justification of convolution operations depending on the evaluation method and the choice of evaluation strategy, which allows it to be used for solving a wide range of tasks. The practical value of the obtained results is that they are used to develop practical recommendations to increase the level of efficiency of information and analytical support of officials.
Thus, the development of the methodology of fuzzy evaluation of information and analytical support of strategic management allowing processing more information and having moderate computational complexity is considered achieved.

\section{Acknowledgments}

The authors' team is grateful for assistance:

to the Doctor of Technical Sciences, Professor Kuvshynov Oleksiy Viktorovych, Deputy head of the Ivan Chernyakhovsky National Defense University of Ukraine.

to the Doctor of Technical Sciences, Professor Rotshtein Oleksandr Petrovych, Professor of the Jerusalem Polytechnic Institute - Mahon Lev.

to the Candidate of Technical Sciences, Associate Professor Bashkirov Oleksandr Mykolayovych, leading researcher of the Central Research Institute of Armament and Military Equipment of the Armed Forces of Ukraine.

\section{References}

1. Rodionov, M. A. (2010). Informatsionno-analiticheskoe obespechenie upravlencheskih resheniy. Moscow, 400.

2. Roy, B. (1996). Multicriteria methodology for decision aiding. Springer. doi: https://doi.org/10.1007/978-1-4757-2500-1

3. Saaty, T. L. (1980). The Analytic Hierarchy Process: Planning, Priority Setting, Resource Allocation. McGraw-Hill, 287.

4. Bellman, R. E., Zadeh, L. A. (1970). Decision-Making in a Fuzzy Environment. Management Science, 17 (4), 141-164. doi: https:// doi.org/10.1287/mnsc.17.4.b141

5. Mamdani, E. H., Assilian, S. (1975). An experiment in linguistic synthesis with a fuzzy logic controller. International Journal of Man-Machine Studies, 7 (1), 1-13. doi: https://doi.org/10.1016/s0020-7373(75)80002-2

6. Sugeno, M. (1985). Industrial applications of fuzzy control. Elsevier Science Pub. Co., 269.

7. Fuller, R. (1995). Neural Fuzzy Systems. Publishing House: Abo Akademi University, 348.

8. Onykiy, B., Artamonov, A., Ananieva, A., Tretyakov, E., Pronicheva, L., Ionkina, K., Suslina, A. (2016). Agent Technologies for Polythematic Organizations Information-Analytical Support. Procedia Computer Science, 88, 336-340. doi: https:/doi.org/ 10.1016/j.procs.2016.07.445

9. Manea, E., Di Carlo, D., Depellegrin, D., Agardy, T., Gissi, E. (2019). Multidimensional assessment of supporting ecosystem services for marine spatial planning of the Adriatic Sea. Ecological Indicators, 101, 821-837. doi: https://doi.org/10.1016/ j.ecolind.2018.12.017

10. Xing, W., Goggins, S., Introne, J. (2018). Quantifying the Effect of Informational Support on Membership Retention in Online Communities through Large-Scale Data Analytics. Computers in Human Behavior, 86, 227-234. doi: https://doi.org/10.1016/ j.chb.2018.04.042

11. Ko, Y.-C., Fujita, H. (2019). An evidential analytics for buried information in big data samples: Case study of semiconductor manufacturing. Information Sciences, 486, 190-203. doi: https://doi.org/10.1016/j.ins.2019.01.079

12. Çavdar, A. B., Ferhatosmanoğlu, N. (2018). Airline customer lifetime value estimation using data analytics supported by social network information. Journal of Air Transport Management, 67, 19-33. doi: https://doi.org/10.1016/j.jairtraman.2017.10.007

13. Ballester-Caudet, A., Campíns-Falcó, P., Pérez, B., Sancho, R., Lorente, M., Sastre, G., González, C. (2019). A new tool for evaluating and/or selecting analytical methods: Summarizing the information in a hexagon. TrAC Trends in Analytical Chemistry, 118, 538-547. doi: https://doi.org/10.1016/j.trac.2019.06.015

14. Ramaji, I. J., Memari, A. M. (2018). Interpretation of structural analytical models from the coordination view in building information models. Automation in Construction, 90, 117-133. doi: https://doi.org/10.1016/j.autcon.2018.02.025

15. Pérez-González, C. J., Colebrook, M., Roda-García, J. L., Rosa-Remedios, C. B. (2019). Developing a data analytics platform to support decision making in emergency and security management. Expert Systems with Applications, 120, 167-184. doi: https:// doi.org/10.1016/j.eswa.2018.11.023

16. Chen, H. (2018). Evaluation of Personalized Service Level for Library Information Management Based on Fuzzy Analytic Hierarchy Process. Procedia Computer Science, 131, 952-958. doi: https://doi.org/10.1016/j.procs.2018.04.233

17. Chan, H. K., Sun, X., Chung, S.-H. (2019). When should fuzzy analytic hierarchy process be used instead of analytic hierarchy process? Decision Support Systems, 125, 113114. doi: https://doi.org/10.1016/j.dss.2019.113114

18. Osman, A. M. S. (2019). A novel big data analytics framework for smart cities. Future Generation Computer Systems, $91,620-633$. doi: https://doi.org/10.1016/j.future.2018.06.046

19. Gödri, I., Kardos, C., Pfeiffer, A., Váncza, J. (2019). Data analytics-based decision support workflow for high-mix low-volume production systems. CIRP Annals, 68 (1), 471-474. doi: https://doi.org/10.1016/j.cirp.2019.04.001 
20. Harding, J. L. (2013). Data quality in the integration and analysis of data from multiple sources: some research challenges. ISPRS International Archives of the Photogrammetry, Remote Sensing and Spatial Information Sciences, XL-2/W1, 59-63. doi: https:// doi.org/10.5194/isprsarchives-xl-2-w1-59-2013

21. Rybak, V. A., Ahmad, S. (2016). Analysis and comparison of existing decision support technology. Sistemniy analiz i prikladnaya informatika, 3, 12-18.

22. Rodionov, M. A. (2014). Problems of information and analytical support of contemporary strategic management. Nauchniy vestnik Moskovskogo gosudarstvennogo tehnicheskogo universiteta grazhdanskoy aviatsii, 202, 65-69.

23. Bednáŕ, Z. (2018). Information Support of Human Resources Management in Sector of Defense. Vojenské rozhledy, 27 (1), 45-68.

24. Palchuk, V. (2017). Suchasni osoblyvosti rozvytku metodiv kontent-monitorynhu i kontent-analizu informatsiynykh potokiv. Naukovi pratsi Natsionalnoi biblioteky Ukrainy imeni V. I. Vernadskoho, 48, 506-526.

25. Mir, S. A., Padma, T. (2016). Evaluation and prioritization of rice production practices and constraints under temperate climatic conditions using Fuzzy Analytical Hierarchy Process (FAHP). Spanish Journal of Agricultural Research, 14 (4), e0909. doi: https:// doi.org/10.5424/sjar/2016144-8699

26. Kljushin, V. V. (2014). Theoretical and methodological basis for the formation and evaluation of the level of the economic system's strategic economic potential. Modern Management Technology, 12 (48). Available at: https://sovman.ru/article/4805/

27. Bogomolova, I. P., Omel'chenko, O. M. (2014). Analysis of influence factors of economic efficiency on the economy of the integrated structures. Vestnik Voronezhskogo gosudarstvennogo universiteta inzhenernyh tehnologiy, 3, 157-162.

28. Sherafat, A., Yavari, K., Davoodi, S. M. R. (2014). Evaluation of the Strategy Management Implementation in Project-Oriented Service Organizations. Acta Universitatis Danubius, 10 (1), 16-25.

29. Alieinykov, I. V. (2018). Analiz faktoriv, shcho vplyvaiut na operatyvnist protsesu zboru, obrobky i peredachi informatsiyi pro protyvnyka pid chas pidhotovky ta vedennia oboronnoi operatsiyi operatyvnoho uhrupuvannia viysk. XVIII naukovo-tekhnichnoi konferentsiyi "Stvorennia ta modernizatsiya ozbroiennia i viyskovoi tekhniky v suchasnykh umovakh". Chernihiv, 38.

30. Alieinykov, I. V., Zhyvotovskyi, R. M. (2018). Udoskonalennia informatsiyno-analitychnoho zabezpechennia za rakhunok formuvannia intehrovanoi informatsiynoi systemy upravlinnia viyskamy. Zbirnyk materialiv VI mizhnarodnoi naukovo-praktychnoi konferentsiyi "Problemy koordynatsiyi voienno-tekhnichnoi ta oboronno-promyslovoi polityky v Ukraini. Perspektyvy rozvytku ozbroiennia ta viiskovoi tekhniky”. Kyiv, 165-166.

31. Kalantaievska, S., Pievtsov, H., Kuvshynov, O., Shyshatskyi, A., Yarosh, S., Gatsenko, S. et. al. (2018). Method of integral estimation of channel state in the multiantenna radio communication systems. Eastern-European Journal of Enterprise Technologies, 5 (9 (95)), 60-76. doi: https://doi.org/10.15587/1729-4061.2018.144085 